\title{
A comparison of in vitro anti-cancer activity of different honey against the colon cancer cells
}

\author{
J. Chai and M. Chopra \\ IBBS, School of Pharmacy and Biomedical Sciences, University of Portsmouth, Portsmouth PO12DT, UK
}

Colorectal cancer is the most common type of cancer in the Western countries. Our diet contains components that can increase or decrease the risk of cancer. Among these, red meat has been highlighted as a food that can increase the risk of colon cancer and fibre is suggested to be protective. ${ }^{(1)}$ Foods with high antioxidant and anti-inflammatory activity are also suggested to be cancer preventive agents. Honey has been well known for its anti-inflammatory and antioxidant activity. ${ }^{(2)}$

In the present study, we set out to examine the anti-proliferative activity of six different honey including unprocessed Pure raw Bee flower \& Sun honey (USA), three varieties of Manuka honey (Active 6+, Manuka $5^{+}$and Manuka 15+), Australian Pure and Gale's commercial honey. Anti-proliferative activity of honey against Caco2 colon cancer cell lines was examined after 24 hour incubation with $10 \%$ honey using imaging and cell toxicity MTT assay. Percentage of viable cells in the MTT assay were calculated relative to cells grown in control media where the absorbance values in the presence of unsupplemented media were normalised to $100 \%$. Since honey contains $30 \%$ glucose and $40 \%$ fructose, effect of $3 \%$ glucose and $4 \%$ fructose was also examined. Results from imaging and MTT assay are shown in figure 1 and table 1 respectively.

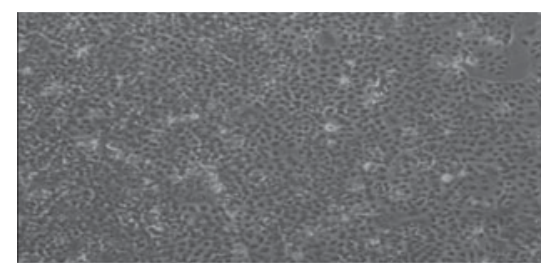

(a) Control

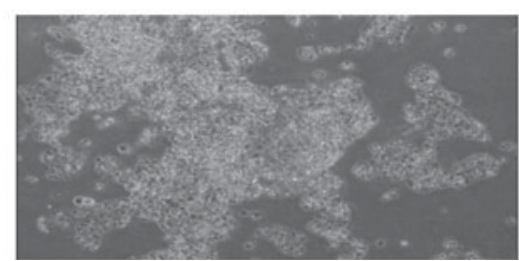

(b) $10 \%$ Pure Raw honey(USA)

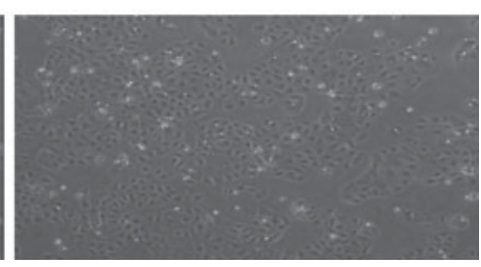

(c) $3 \%$ glucose plus $4 \%$ fructose

Fig. 1. Images of caco 2 cells incubated for 24 hours in unspplemented (a) and media containing $10 \%$ honey (b) and $3 \%$ glucose and $4 \%$ fructose (c).

Table 1. Caco2 cell viability in the presence of $10 \%$ final concentration of different honey

\begin{tabular}{|c|c|c|c|c|c|c|}
\hline & Pure Raw (USA) & Rowse Manuka $5+$ & Active Manuka 6+ & Rowse Manuka $15+$ & Australian Pure & $\overline{\text { Gales honey }}$ \\
\hline Percent cell viability Mean (SD) & $\mathrm{a}_{33.2(3.9)}$ & $37.7(2.3)$ & $38.0(4.3)$ & $\mathrm{b}_{4} 47.7(1.1)$ & ${ }^{\mathrm{b}} 45.3(5.4)$ & $\mathrm{b} 45.7$ (4.3) \\
\hline
\end{tabular}

Results are average of experiments done on four different occasions with 5 replicates done at each time. Those not sharing a similar superscript were significantly different at $p<0.05$ (Mann Whitney test).

Results show reduction in caco2 cell viability in the presence of all honey, however unprocessed pure raw honey showed the highest effect. Percent cell viability was $89 \%$ in the presence of $3 \%$ final concentration of glucose, $\sim 87 \%$ in the presence of fructose and $~ 70 \%$

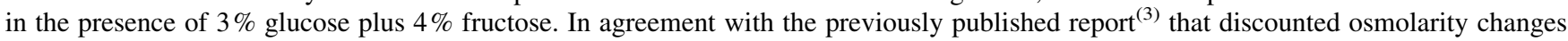
being a significant factor in honey's anti-proliferative effects against the bladder cancer cell lines, our results show that other factors besides sugar are likely to contribute to honey's effect on cell viability. In our study, honey was also found to effect BrDu incorporation and distribution within the cell cycle., Flow cytometry analysis showed that compared to control, there was a significant reduction of cell number in $\mathrm{G} 0 / \mathrm{G} 1$ phase $(P<0.005)$ and increase in number of cells in the $\mathrm{S}$ phase $(P<0.05)$.

In conclusions, results of present investigation highlight cancer interception potential of honey in an in vitro model of colon cancer cell line.

1. World Cancer Research Fund. (2009) Continuous update project report on colorectal cancer.

2. Kassim M et al. (2010) Nutr Res 30(9): 650-9.

3. Swellam T et al. (2003) Int J Urol 10(4): 213-9. 